\title{
Antropologia e visualidade no contexto indígena ${ }^{1}$
}

\author{
Sílvia Pizzolante Pellegrino
}

\begin{abstract}
resumo A elaboração e a transmissão continuada de sons e imagens são aqui abordadas como um constante movimento que vai além dos produtos fílmicos, revelando um processo de construção de imagens e auto-imagens. Para essa análise, foi dada especial importância às formas de representação em filmes e vídeos etnográficos, um gênero decorrente do movimento documental, que tem no realismo e nas formas de alteridade seus elementos centrais. No decorrer do trabalho, o problema das formas de representação dá lugar a um complexo evento comunicativo, que por sua vez articula diferentes concepçóes de visualidade. A emergência de um evento reflexivo audiovisual entre sociedades indígenas modifica não só os termos do diálogo com a sociedade envolvente, como indica importantes abordagens para a imagem no campo da investigação antropológica, que, para além das formas de representação, se inscrevem no campo das concepções de visualidade.
\end{abstract}

palavras-chave Audio-visual. Parceria. Realismo. Concepções de visualidade. Diferença.

\section{Introdução}

O presente artigo tem caráter mais ensaístico do que etnográfico. Trata-se de um balanço interpretativo da produção literária e audiovisual sobre o tema das imagens em suas relaçóes com contextos indígenas, assim como em relação à antropologia.

A reflexão se inicia com uma referência ao realismo como uma dimensão fundadora do registro audiovisual. Essa perspectiva desdobrase posteriormente em novas possibilidades de construção de sentidos: tomam corpo procedimentos de expressão em que o ponto de vista do sujeito por trás das câmeras compartilha com seu objeto a subjetividade que dá forma ao real apreendido.

A disciplina antropológica é aqui abordada na medida em que esta foi concebida segundo essas inversóes e inquietaçôes, que se tornam ainda mais evidentes nas suas produções audiovisuais. Assim, da construção objetiva da realidade, presente nos primeiros documentários etnográficos, tem-se a passagem para a explicitação dessa construção, que passa a constituir o projeto da antropologia compartilhada.

Nas discussóes mais recentes sobre o tema das imagens na antropologia, especificamente em relação a alguns grupos indígenas brasileiros, têm-se importantes contribuições, em especial dos autores com os quais dialogo no decorrer do texto, entre eles: Turner (1993), Ginsburg (1995), Feldman Bianco e Moreira Leite (1998), Caiuby Novaes (2000), Frota (2000) e Gallois (2002). Em tais abordagens, os projetos de documentação audiovisuais etnográficos só adquirem sentido se levarem em conta os contextos de enunciação em que são produzidos, pois dessa forma constituem uma experiência comunicativa.

Nessa direção, torna-se fundamental uma referência cuidadosa ao Projeto de Documentação Video nas Aldeias (Gallois; Carelli, 1993) ${ }^{1}$, por mobilizar exemplarmente os conteúdos dessas discussóes em seus vídeos e textos.

1. Conjunto de trabalhos sobre o tema da capacitaçấo e produçáo de materiais audiovisuais em parceria com grupos indígenas brasileiros, realizado entre as décadas de 1980 e 1990 no âmbito da ONG CTI (Centro de Trabalho Indigenista). 
Influenciada por essa perspectiva, acompanhei o período inicial de um curso de capacitação para a produção audiovisual realizado em uma aldeia Wajápi, no estado do Amapá, durante um mês do ano de 2002.

Por terem participado de numerosas produçôes do Programa de Documentação Vídeo nas Aldeias, os Wajāpi apresentaram reflexôes muito estimulantes sobre as imagens e sua produção. Após algumas entrevistas concedidas a mim pelos Wajápi, a pesquisa sobre a imagem na antropologia em contextos indígenas apontou para o terreno que se refere às concepçóes da imagem.

Assim, a costura final do texto indica as importantes relaçóes estabelecidas entre os sistemas audiovisuais e as esferas mais amplas de experiências sensoriais em diferentes contextos cosmológicos. Essa articulação representa uma grande contribuição dos sons e imagens no âmbito da disciplina antropológica. Estas são as linhas gerais do texto que aqui segue.

\section{A prática documental}

Os primeiros registros etnográficos visuais como discursos realistas e objetivos revelam, segundo a crítica pós-moderna, a elaboração de convençôes narrativas ocidentais sobre a alteridade: a separação, inscrita institucionalmente na antropologia, entre "nós" e "eles" se inscreve também na estruturas dos filmes etnográficos.

Com o surgimento de novas tendências narrativas, esse quadro de distanciamento binário de documentação objetiva deu lugar aos movimentos estéticos participativos, que indicavam o registro das imagens como um produto da agência humana por trás das câmeras.

Seja no sentido do distanciamento ou da intervenção, o que está em questão é a produçấo de uma subjetividade como mediadora dos termos da relação estabelecida entre as partes. O realismo inicial dá espaço à criaçáo de agências de interaçáo e produção de sentidos. Da representação naturalista à mobilização dos termos do real: este é o ambiente no qual a reflexividade assume suas formas.

A prática reflexiva no audiovisual, portanto, se inscreve na conjunção de duas discussóes: sobre os modos de fazer cinema etnográfico como construçôes rigorosas e verificáveis, e o crescente interesse nos procedimentos compartilhados de expressão, nos quais as manifestaçóes do ponto de vista do autor projeta a dimensão da subjetividade como um elemento constitutivo da representação do real.

Os termos do realismo e da reflexividade na construção de sentido das criaçôes audiovisuais constituem um espaço de negociação no qual as partes envolvidas interagem de forma fluida.

No âmbito das produções audiovisuais realizadas em regime de parceria com sociedades indígenas brasileiras, as novas perspectivas comunicacionais reflexivas indicam que o evento fílmico não se limita às imagens produzidas, mas deve ser considerado um espaço híbrido de invenção criativa. $\mathrm{O}$ evento de produção e transmissão audiovisual articula, assim, um espaço de fronteira e enunciação cultural, que pressupóe um sistema de comunicação continuada entre os agentes envolvidos.

O debate relevante nesse tema consiste em pensar sobre como a construção dessa nova narrativa reflexiva estabelece uma experiência audiovisual de formação de imagens e auto-imagens, não somente pelas formas de semelhança analógicas, mas também pela construção de diferentes visualidades e instâncias de representaçáo, presentes no espaço entre o visível e o que não pode ser visto. 


\section{Realismo, reflexividade e alteridade}

As experiências iniciais das imagens cinematográficas foram constituídas pela coexistência de elementos realistas e ilusionistas: o espanto da chegada do trem à estação parece nunca ter se separado da certeza de que, afinal, não se tratava de um trem (Weinberger, 1994). Esse duplo sentido da experiência já conjugava a pseudo-oposição entre a ficção, construída pelo ilusionismo de Meliès em 1897 - pertencente ao plano do imaginário - e a realidade documentada e guiada pela experiência, inaugurada pelos filmes de atualidades dos irmãos Lumière em 1895 (De Brigard, 1975)².

As diferentes posturas elaboradas frente ao evento fílmico: ora como uma concepção de função indicial da realidade pela sua captura na emulsão do celulóide, ora como uma consideração sobre o processo fílmico como auto-referente - que necessariamente se inscreve na realidade "apreendida" (Banks, 1992) e a molda -, indicam um jogo explícito entre a realidade e sua representação. As construções teóricas que questionam essa divisão conceitual afirmam ainda que a ficção permeia todas as construções fílmicas na medida em que se trata de eventos narrativos (Loizos, 1992; Renov, 1993) que muitas vezes podem apresentar elementos que dependem mais da ação da imaginação que da realidade (Vernet, 1995).

Os princípios de ficção e realidade se relacionam de maneira contraditória: o automatismo

2. No ano de 1914 surgiram os híbridos documentaire romancé - filmes ficcionais ambientados em locaçôes "genuinamente" exóticas (De Brigard, 1975). Estudos fílmicos posteriores apontaram também novas perspectivas sobre essa diferenciação: a mediação da câmera como uma condição prévia de interpretação, que equivale às construçôes ficcionais (Renov, 1986), ou ainda pelo desdobramento dessa posiçáo, que indica o elemento de realismo documental na indexação do público diante do filme (Carroll, 1996). Sobre essa discussão ver também Freire (1998). do registro fotoquímico não existe separadamente da agência humana - a produção e negação entre as realidades e suas representaçóes configuram um quadro de ambigüidade ontológica. Assim, embora exista o registro objetivo - químico ou magnético das coisas representadas -, fatores subjetivos influenciam sua realização (Henley, 1999).

Essa tensão estabelecida sobre o real apreendido e construído nos conduz a um esforço de reflexão a respeito dos termos da dualidade entre objetividade e subjetividade - o terreno de base que fundamenta os aspectos da prática reflexiva. Esse é o fio condutor a partir do qual se articula o espaço aberto pelos suportes audiovisuais de registro etnográfico e a antropologia como uma construção narrativa ${ }^{3}$.

O diálogo entre os suportes visuais e a antropologia foi empreendido pelo cinema etnográfico, já por volta da década de 1920, como um gênero que trata das relaçóes de alteridade. Os primeiros filmes etnográficos constantes dessa época tiveram como contexto a perspectiva da construção realista da totalidade observada: Rituais e Festas Bororo (1917) e Nanook of the North (1922).

$\mathrm{Na}$ década de 1960, novas articulaçôes e perspectivas estéticas foram estabelecidas entre os filmes etnográficos e a nouvelle vague francesa, o neo-realismo italiano e, sobretudo, a vanguarda russa, representada por Dziga Vertov. Essa reorientação recolocou os termos da relação entre realismo e ficção: importa mais a verdade do filme do que a verdade no filme (Rouch, 1995).

Tais percursos das imagens documentais etnográficas permitem localizar um elemento

3. Nesse sentido, Nichols (1981) aponta os filmes etnográficos como um subgênero dos documentários realistas, que na direção da proposta de Wiseman oferecem a oportunidade de considerarmos os diferentes níveis de realismo e abstração das narrativas fílmicas. 
central no tema das relações de alteridade uma espécie de terreno de base sobre o qual se observam as mais diversas experiências estéticas. O conjunto de filmes que consolidou a prática etnográfica audiovisual representou, portanto, tanto um espaço para as imagens no âmbito da disciplina antropológica, na esteira de Margaret Mead ${ }^{4}$, como abriu caminhos, na perspectiva de Jean Rouch, para o sentido do compartilhamento da experiência do encontro entre investigadores e investigados em toda a sua complexidade.

O realismo torna-se, num certo sentido, o epicentro dessas experimentaçôes: na década de 1920 consolida-se como um discurso da retórica científica, e, na década de 1960, como um projeto estético que inclui as construçôes ficcionais. A discussão que merece relevância diz respeito ao realismo construído pela câmera, em lugar de uma apreensão realista dos fatos.

Houve assim um deslocamento do sentido da documentação audiovisual etnográfica: de uma busca pela apreensão do real, vinculada ao período clássico da antropologia, para as subversôes narrativas empreendidas na década de $1960^{5}$. Em tais subversōes, o critério da apreensão realista da totalidade é desconstruído pela perspectiva polifônica, da qual participam as diversas vozes produtoras do encontro etnográfico.

Essa rotação de perspectiva na estética dos filmes etnográficos, partindo da retórica funcionalista em direção à antropologia compartilhada proposta por Rouch, alinha-se à abordagem adotada por Leach, pela qual "a única etnografia da qual um antropólogo social tem um conhecimento íntimo é a que deriva

4. Suas reivindicações fundaram uma nova abordagem antropológica, que considera os métodos audiovisuais possibilidades de prática investigativa (Mead, 1985)

5. Petit à petit (1954), Le maitres fous (1955) e Jaguar (1967). de sua própria experiência de vida" (Leach, 1978 , p. 8). A cultura, na perspectiva do autor, é interpretada de acordo com a abordagem antropológica de Dell Hymes $(1967)^{6}$ : como uma comunicação - uma interconexáo complexa que transmite informaçóes àqueles que dela participam.

Nesse sentido, há um alinhamento da proposta comunicativa de Dell Hymes (1967) e Leach (1978) com a reorientação do foco da descrição etnográfica colocada pela crítica cultural norte-americana, entre as décadas de 1970 e 1980, sobre os processos de mediação nas construçôes narrativas. Nesse período a antropologia repensou o encontro etnográfico de "sujeitos" com "objetos" a partir das categorias de troca e negociaçáo entre as partes. Dessa forma, a autoridade das descriçôes culturais homogêneas deu lugar à perspectiva de fluxos culturais em dinâmicos processos de negociação com os contextos locais, tanto externos quanto internos ao grupo (Marcus; Fischer,1986; Gallois, 2002).

O desdobramento dessas perspectivas antropológicas nos produtos audiovisuais etnográficos indicou que, em vez da exploração sobre a essencialidade ontológica da imagem num sentido de apreensão realista do objeto, buscou-se a construção narrativa polifônica e reflexiva ${ }^{7}$.

6. Dell Hymes apontou primeiramente as abordagens etnográficas de acordo com a leitura de eventos comunicativos: "Creio ser mais provável que os antropólogos não tenham visto claramente como conjugar 'comunicaçáo' com algo especificamente etnográfico como objeto de seu interesse e de seu estudo [...] a necessidade de considerar problemático o que seja comunicativo numa cultura, de determiná-lo através de cuidadoso trabalho etnográfico em termos de sistema de estudo. Somente sobre tal base pode a antropologia contribuir com descrições válidas e reveladoras dos padrôes de comunicaçáo de comunidades reais" (1967, p. 36).

7. A arca dos Zo'é(1993). 
Assim, o abandono da construção do realismo em direção a um realismo da construção, deflagrada pela antropologia compartilhada, aponta a narrativa audiovisual como uma linguagem que tem na reflexividade seu elemento constitutivo.

$\mathrm{O}$ aspecto que merece atenção nesse processo é a utilização de conceitos cinemáticos para a reflexão sobre as formas ativas produtoras de representaçóes e auto-representaçóes. Esse diálogo conceitual se dá tanto no âmbito das produçóes audiovisuais quanto no ambiente teórico que permeou essa interação: a construção do objeto da etnografia pós-moderna.

A proposta reflexiva recoloca a relaçáo estabelecida com os objetos da documentação numa nova abordagem estética de apreensão do real tal como ele é vivenciado. A superação da dicotomia entre realidade/ficção ou objetividade/subjetividade permite o acesso ao sistema de significados da experiência audiovisual como situaçóes de intercâmbio entre os diferentes sujeitos envolvidos.

Essa abordagem reflexiva privilegia não as imagens e sons como tais, mas a tradução da experiência do processo criativo de comunicação intercultural pela troca continuada de pontos de vista. Trata-se assim do aparato conceitual utilizado na reflexão sobre as formas de alteridade e auto-imagem estabelecidas no diálogo entre diferentes instâncias discursivas e performáticas.

\section{Polifonia, comunicaçáo e mediação}

As experiências audiovisuais realizadas em regime de parceria com populações indígenas brasileiras ${ }^{8}$ representam essa reorientação nas relaçôes constitutivas do encontro etnográfico. Trata-se da elaboração de um espaço de interlocução pela produçấo e retransmissão continuada de imagens e sons, acionando e

8. Ver principalmente produçóes do Projeto Vídeo nas Aldeias (CTI) e o filme Taking aim: aldeia global. (1993). potencializando uma série de performances gestuais e narrativas orais.

O valor estético dos vídeos é relevante somente se levarmos em conta o contexto de enunciação de uma experiência comunicativa, pois o que precisa ser enfatizado é a abertura de um novo espaço discursivo de representação, que vai além do documento audiovisual, estabelecendo um processo social de mediaçáo (Ginsburg, 1995; Turner, 1993; Frota, 2000) no qual deve ser dada uma atenção aos significados culturais desvendados pelas imagens, "bem como às formas como a produção e a leitura dessas imagens são mediadas [...]" (Feldman-Bianco \& Moreira Leite, 1998, p. 12).

Os trabalhos audiovisuais reflexivos são singulares por possibilitarem a abertura de um novo espaço discursivo para os meios de comunicação indígena nos quais a atenção dada aos processos de produção e recepção vai além das análises formais dos filmes indígenas como textos (Ginsburg, 1995). Essa dinâmica de comunicação representa também a possibilidade de criação de estratégias peculiares na construção e reconstrução de imagens e auto-imagens (Nichols, 1994), e o que se produz a partir disso vai além do documento audiovisual (MacDougall, 1998).

Segundo Gallois; Carelli (1995), a respeito da experiência realizada entre os Wajāpi, a utilização do audiovisual leva a uma revisão da auto-imagem a partir da possibilidade de reordenaçấo do tempo e do espaço nos quais cada grupo se situa. Novas continuidades são criadas pelas informações transmitidas pelo vídeo que

propiciaria, de forma única, uma consciência de mudança, indispensável para a formulação de açōes visando o controle do convívio interétnico (1995, p. 211).

Os elementos de visibilidade e a polifonia formadores do suporte comunicativo audiovisual - permitem a circulação coletiva de informaçôes 
ativando mecanismos de apropriação e significação próprios às sociedades de transmissão oral (Gallois; Carelli, 1995; Caiuby Novaes, 2000; Frota, 2000). De maneiras diferentes, os recursos do audiovisual são empregados quando se problematiza a criação de continuidades, seja na polifonia da investigação etnográfica, seja em um processo complexo de associaçóes envolvidas na produção de saberes.

Na perspectiva de Gallois; Carelli, essa forma de transmissão coletiva das informaçóes "propicia uma mudança na forma e no conteúdo das associações envolvidas na produção da auto-representação" (1993, p. 35) ${ }^{9}$. Ocorre assim uma efetiva transformação na lógica do saber pela construção coletiva de conhecimentos diferentes, tanto pelo conteúdo das informações exibidas quanto pela forma de apropriação. A circulaçáo dos elementos audiovisuais tem, nesse contexto, impactos próprios e autosuficientes que permitem esse movimento de auto-reflexão.

Nessa direção, a possibilidade de abertura para o exterior em detrimento da idéia de fechamento para o aspecto interno resulta na criação de novos pólos de poder ${ }^{10}$. Ao analisar a experiência de inclusão dos elementos audiovisuais entre o grupo Kaiapó, Turner indica que tipos diferentes de mediaçáo ocorrem no vídeo indígena. $\mathrm{O}$ ato da elaboração de um vídeo por um membro do grupo começa a "mediar" uma variedade de relações políticas e sociais dentro da comunidade indígena de uma maneira distinta da situação em que o videomaker é uma pessoa de fora, como na

9. A retransmissão compartilhada abordada pelos então autores do projeto foi precedida pelos processos adotados por Flaherty entre os esquimós e, mais tarde, por Rouch na África (Rouch, 1995).

10. Sobre a inserção do artista na vida política de seu grupo, Barcelos Neto (1999) indica que na arte e na estética Waurá, “julga-se muito mais 'quem' pintou a obra do que 'o que' foi pintado; esse também é um julgamento moral da pessoa” (p. 17). maioria dos filmes antropológicos e documentários. Nas palavras do autor:

Os Kaiapó fizeram rapidamente a transição do vídeo como um meio de gravar os eventos para um evento a ser gravado (Turner, 1993, p. 87).

Um dos principais desdobramentos dessa nova perspectiva de mediação cultural na qual o processo de produçáo é efetuado pelo videomaker indígena implica o fato de que este compartilha com o seu objeto as mesmas categorias, noções de representação e princípios estéticos na atribuição da importância social e política ao que está sendo registrado (Turner, 1993).

A tradução em imagens e sons do ponto de vista "interno" do sujeito do registro em relaçáo ao seu objeto como um importante significado potencial dos filmes reflexivos teve sua experiência pioneira em Navajos Filmmakers (Worth; Adair, 1979; France, 1998). Nesse estudo, os autores estavam convencidos da possibilidade da existência de um modelo de organização visual dos eventos, uma lei normativa que tornasse a comunicação visual possível para o entendimento dos padróes de imagens, regras e modelos de comunicação visual próprios do contexto cultural dos Navajo (Worth; Adair, 1979).

A questão que prevalece desse contexto são as relações que se estabelecem entre o conjunto de especificidades culturais e as diferentes construções interpretativas pelas lógicas de apropriaçâo discursiva e de transmissão coletiva que, por sua vez, configuram diferentes padrôes de visualidade.

As produçóes de realizadores indígenas do projeto Vídeo nas Aldeias $(\mathrm{CTI})^{11}$, tratam do processo de reflexão pelo qual o indígena se torna sujeito e objeto da documentação num sentido diverso de Worth; Adair: a imagem em sua

11. Jane Moraita: nossas festas (1995); Tem que ser curioso (1996); Hepari Idub'rada: obrigado rrmão (1998); e Wapte Mnhônõ: iniciaçâo do jovem xavante (1999). 
relação direta com a memória, a comunicação entre diferentes geraçôes, a visibilidade de minorias e as diferenciaçôes culturais.

Longe de representarem apenas produçôes excessivamente metalingüísticas, esses temas que prevalecem nas construçóes narrativas, marcam a revelação de

um processo político-cultural de adaptação criativa que gera as condiçôes de possibilidade de um campo de negociação interétnica em que o discurso colonial possa ser contornado ou subvertido (Albert, 2002, p. 241).

A intertextualidade cultural do contato implica o fato de que o complexo de representaçóes resultantes do processo comunicativo interétnico não se limita às imagens criadas reciprocamente entre índios e brancos, mas ao fato de que

[...] a auto-representação dos atores interétnicos constrói-se na encruzilhada da imagem que eles têm do outro e da sua própria imagem espelhada no outro (Albert, 2002, p. 241).

Esse complexo de representações no âmbito do espaço fílmico é parte de uma composição de cena na qual todo o arcabouço de informaçôes de gestos e palavras articula imagens e sons que tornam concreto o fenômeno comunicativo. A construção da narrativa, assim como sua retransmissão, transmite valores compartilhados e reconhecimentos simbólicos no interior do grupo na mesma medida em que propóe um diálogo com a audiência externa em primeira pessoa (Gallois; Carelli, 1998).

A criação das identidades ${ }^{12}$ não se dá como um movimento isolado da fala de um grupo

12. Sobre as identidades étnicas, ver Carneiro da Cunha (1986a, 1986b, 1995). Segundo a autora, a etnicidade é uma linguagem na medida em que permite uma comunicação que nas situaçóes de contato tende a acentuar as diferenças, inclusive em processos eminentemente políticos. em direção à audiência, mas como narrativas polifônicas que se produzem no contexto da constante retransmissão. Em outras palavras, a formação de identidades e auto-imagens potencializadas pela introdução dos recursos audiovisuais não se restringe à elaboraçẫo de um discurso para a audiência externa, mas ocorrem pela veiculação de informaçóes como um todo, inclusive no âmbito do próprio grupo. Dessa forma, a transmissáo continuada torna-se um elemento central desse processo.

Segundo essa perspectiva, Gallois (2002) indica que os discursos indígenas formulados para a sociedade nacional remetem a lógicas culturais subjacentes aos processos enunciativos de identidade e alteridade. A autora reitera a proposta de Marcus \& Fischer (1986) sobre a reorientação de foco na descrição etnográfica, que deve levar em conta não só as perspectivas locais de produção de discursos, mas estas em relação ao processo de diálogo cultural estabelecido entre culturas locais. Os fluxos culturais em contínuo estado de resistência e acomodação devem ser privilegiados, tanto no âmbito do grupo local quanto externo a ele (Gallois, 2002).

Esse constante processo reflexivo permite pensarmos a formação de identidades no seu sentido mais amplo, no qual os elementos de polifonia e transmissão das operaçóes de comunicação estão em jogo nas produções audiovisuais como uma prática reflexiva de enunciação discursiva.

A esse respeito, Frota, que no ano de 1985 iniciou um projeto de documentação audiovisual entre os Kaiapó, afirma que o

controle dos Kaiapó sobre a forma com que são representados com 'índios hi-tech' é também uma afirmação culturalmente relevante da identidade Kaiapó, visto que eles concebem sua cultura tanto do ponto de vista da permanência quanto do ponto de vista da transformação [...] (2000) $)^{13}$.

13. Processo retratado no filme Taking aim: aldeia global (1993). 
O conceito da fronteira de Hannerz (1997) como um espaço de transformaçáo e mobilidade pode também traduzir o espaço aberto por essa possibilidade de produção e transmissão de conteúdos orais e performances audiovisuais, na medida em que:

Freqüentemente é nas regiōes fronteiriças que as coisas acontecem, e hibridez e colagem são algumas de nossas expressōes preferidas por identificar qualidades nas pessoas em suas produçôes (Hannerz, 1997, p. 8).

Na mesma direção, Appadurai (1996) indica que a mediaçáo eletrônica transforma os modos de comunicação e de conduta preexistentes em forças que impelem o mundo da imaginação. Nessa atividade de criação e recriação, os processos de comunicação pela produção e retransmissão de informaçōes não se colocam como a história das homogeneizaçóes culturais, mas como o espaço de formação de subjetividades particulares.

Essa atmosfera conceitual acerca da elaboração privilegiada de uma tradução cultural no espaço de fronteira, possibilitada pela retransmissão de performances e conteúdos veiculados oralmente pela experiência de visualidade em seu sentido mais amplo, recoloca também o foco da discussáo, que passa do externalista/internalista para a diversidade/diferença (Gallois, 2002).

O espaço audiovisual certamente é um lugar que permite a articulação de discursos de enunciação criativa e situacional pela capacidade de alinhamento com as tradiçôes orais, visuais e performáticas de transmissão coletiva (Gallois; Carelli, 1995) ${ }^{14}$.

Como sugere Chalfen (1992), no processo de virtualidade dinâmica da comunicação audiovisual devemos abdicar da idéia das homogeneida-

14. Sobre a identificaçẫo de um espaço de inscrição das identidades como uma experiência de auto-imagem que vai além da representação como consciência analógica da semelhança, constituindo uma consciência transcendida e fluida, ver Bhabha (1998). des culturais para aceitar a noção de pluralidade, o que resulta numa complexidade de estilos e modelos de representação. Assim, segundo o autor, as relaçôes entre as expressóes audiovisuais e os conteúdos culturais só adquirem sentido se analisadas em termos do seu potencial comunicativo.

\section{Tecnologias, visualidade e pensamento}

O sentido reflexivo da comunicaçáo audiovisual reside menos na questáo da apropriação dos recursos tecnológicos e mais nas possibilidades de tradução e transmissão de estratégias e discursos. Trata-se de uma série de eventos criativos na formação de identidades, imagens e auto-imagens no âmbito de um sistema polifônico de narrativas.

A visibilidade desse jogo é a prática reflexiva. Em outras palavras, independentemente de a manipulação da câmera pelos cinegrafistas indígenas se dar de maneira completa ou parcial, interessa o fato de que o contexto de enunciação de discursos e construção de narrativas se inscreva nas imagens. $\mathrm{O}$ sentido comunicativo das "falas-imagens" 15 está também na forma participativa de sua transmissão (Gallois; Carelli, 1995) e no seu contexto de produção. A importância dos processos de transmissão se dá tanto no âmbito do próprio grupo quanto para a audiência externa, indígena e não-indígena ${ }^{16}$.

15. Termo utilizado por Gallois; Carelli (1993), a respeito da experiência da utilização das imagens em vídeo entre os Wajápi.

16. Ao contrário do que ocorre nos programas como a série britânica Desappearing world (Singer, 1992), e no trabalho de Eric Michaels sobre a televisão aborígene no deserto central da Austrália (segundo Turner (1993), um dos mais importantes em termos de teoria de apropriação dos meios audiovisuais), a autodocumentação cultural indígena brasileira tem um ciclo de transmissão bastante restrito. Ainda assim, o desafio acerca das relaçóes que se estabelecem entre os agentes indígenas e a audiência num determinado contexto histórico, social e cultural (Singer, 1992), se mantém. 
Nesse contexto de reflexões sobre o sentido atribuído às tecnologias da imagem entre os grupos indígenas participantes de processos de elaboração de materiais audiovisuais, acompanhei, durante o mês de janeiro de 2002, as oficinas iniciais de capacitação para a elaboração de um filme na aldeia de Mariry, área indígena Wajāpi, no Estado do Amapá ${ }^{17}$. Nas entrevistas realizadas entre os Wajápi, ao longo do período em que pude acompanhar esse trabalho, sempre procurei indagar sobre a demanda interna para a produção de materiais audiovisuais, tanto em relação aos não-índios e a outros povos indígenas quanto em relação aos próprios Wajápi.

As respostas que obtive nas entrevistas podem ser divididas em três temas principais: 1 ) o filme como um veículo de comunicação e elemento de troca com outras sociedades indígenas e de interlocução política com a sociedade brasileira; 2) o potencial da narrativa audiovisual na manutençáo dos aspectos de rememoração e reinterpretação garantidas pela transmissão oral no âmbito do próprio grupo; 3) as possibilidades de visualização e encenação ${ }^{18}$.

Esses depoimentos contribuíram para a reflexão de que, não obstante ao tema das mediaçóes e suas potencialidades comunicativas tratadas anteriormente, os sentidos da experiência audiovisual têm significados estritamente ligados às construções da imaginação. Tratam das diferentes concepçóes de realidade, situando-se em um terreno do qual fazem parte os aspectos e práticas cosmológicas dos agentes envolvidos. As possibilidades de manipulação

17. A partir do ano 2000, o trabalho de capacitação e parceria com os Wajápi para a produção de materiais audiovisuais vem sendo organizado de uma maneira mais sistemática por profissionais vinculados ao Programa Wajâpi, composto por uma equipe responsável por assessoria direta aos indígenas, por meio de açóes educativas, e que está no momento passando da gestâo do CTI ao da ONG Iepé.

18. Para o acesso as entrevistas e suas análises, ver o texto integral da dissertação. do espaço/tempo narrativo audiovisual são exercícios de imaginação:

o importante nesse ponto é observar que reagimos diante da imagem fílmica como diante da representação muito realista de um espaço imaginário que aparentemente estamos vendo...

(Aumont, 1995, p. 21).

Diferentes concepçóes de realidade articulam diferentes sistemas de visualidade - esse aspecto merece relevância nos estudos antropológicos das formas audiovisuais.

Como exemplo dessa abordagem, Peter Gow (1995) investiga a experiência com o meio cinematográfico para os nativos do Alto Ucayali. A experiência visual, segundo o autor, produz outras imagens da realidade, mediadas por maneiras diferenciadas de compreensão. Assim, a realidade das imagens ou da vida não existe: a visão das aparências, do mesmo modo que das imagens dos filmes, é uma contra-imagem da realidade.

Os valores atribuídos às experiências de visualidade articuladas pela experiência do cinema analisada por Gow (1995) indicam sua inserção num sistema mais amplo de experiências significativas, com tons intrinsecamente locais.

As experiências com os dispositivos audiovisuais tratam de vivências surgidas dentro de sistemas compartilhados de significação e classificação do real, anteriores ao evento audiovisual, mas que o incorporam. As formas de visualização estão, portanto, muito além dos aspectos figurativos: são experiências que estruturam diferentes sistemas estéticos, cujos produtos são reflexôes sobre as condiçôes de humanidade (Müller, 1992; Gow, 1999).

As possibilidades de visualização são um produto do conhecimento que indica as diversas formas de concepçáo da realidade em suas diferentes manifestações. Segundo essa perspectiva, os padrões de pintura corporal são igualmente exemplos de experiências visuais: 
O padrão é uma experiência visual, e, como observei, aponta para o interior oculto do objeto que recobre. No entanto, isso é verdade no que se refere à visão humana normal. Os Piro postulam muitas maneiras possíveis de ver o mundo (Gow, 1999, p. 310).

Os alucinógenos ${ }^{19}$, assim como o audiovisual e os grafismos indígenas, correspondem ao que Vidal (1992) denominou de "sistemas de comunicação visual”, que permitem a visualização do que normalmente não está visível. Como nos mostrou Gow (1999) em relação aos Piro, esses sistemas possibilitam que seres normais penetrem

no mundo das transformaçóes. Essas formas de arte visual dialogam umas com as outras, reiterando constantemente o significado do visual no mundo Piro, chamando atenção para certos modos de ver e afastando-se de outros (Gow, 1999, p. 313).

A construção de realidades e contra-realidades, a partir de visualizações ou de padrōes estético ${ }^{20}$ faz sentido para o entendimento das cosmologias envolvidas na medida em que são

19. Para os nativos do Alto Ucayali, o acesso visual proporcionado pelo cinema remete à experiência do ayauasca como atualizaçóes dos mecanismos de manutenção da vida social em termos de uma composição segura que une exterior e interior. Sobre essa abordagem, ver Gow (1995).

20. Ingold (1998) traz o debate sobre as relaçóes entre antropologia e estética na perspectiva de categorias "trans-culturais" implícitas ou explícitas que são utilizadas nos processos de traduçáo cultural. Segundo o argumento do autor, a categoria "trans-cultural" não configura uma questão antropológica. Importa para a antropologia, a exemplo do trabalho de Lévi-Strauss com as máscaras africanas, o uso de critérios estéticos, não para a comparação com as estéticas de outras culturas, mas como perspectivas estéticas próprias à determinada cultura. Sobre a questão da estética e arte primitiva, ver também Price (2000). apreendidas formas de expressão, comunicação e significação que não se reduzem aos seus aspectos figurativos. Nessa direçâo, as "manifestaçôes artísticas" são tomadas como um valor transformativo que age sobre o tempo e permite sua visualização.

No mesmo sentido, quanto às relaçóes possíveis entre os sistemas de representação da visualidade e as práticas cosmológicas de significação, Van Velthem (1995) indica que as pinturas Wayana são formas de expressão e comunicação nas quais os procedimentos artísticos remetem a outros tempos, os tempos primordiais. Segundo a autora, os Wayana não trabalham com recriação, mas com transposição, encurtamento do tempo. As imagens concebidas mediante essa "visáo" de outras realidades têm mais a função de fazer ver do que de serem vistas.

A visualidade e a estética possuem um valor comunicativo e constituem uma constante recriação do mundo visível, dando acesso a aspectos obscuros na visão ordinária. Os estudos cosmológicos que derivam dessas apreensóes devem, portanto, incluir as relaçôes que os homens "mantêm com sua imaginação e seu imaginário" (Augé, 1997, p. 77), para que se perceba o sentido da visualidade, e, assim, da experiência audiovisual.

Barcelos Neto, numa direção semelhante, busca o valor comunicativo da arte Waurá como uma via de acesso às categorias de pensamento ou entendimento do cosmo: uma experiência sensorial, e, assim, um discurso visual que o autor denominou de "arcabouço conceitual da imagem” (Barcelos Neto, 1999, p.7).

Os valores estéticos e artísticos manifestados pelas figuraçôes, grafismos e imagens estão diretamente relacionados a sistemas específicos e diferenciados de comunicaçáo, inclusive com as alteridades sobrenaturais. $\mathrm{O}$ autor atribui à circulação e à crítica estética das produçôes artísticas traços importantes do sistema sociopolítico Waurá. 
As manifestações artísticas, os valores estéticos e as imagens em relação às sociedades indígenas têm uma estreita relação com o universo das experiências sensoriais, que se distanciam da experiência do figurativo para englobar outras esferas da existência.

As diferentes manifestaçôes da noção de imagem, portanto, devem ser pensadas a partir do contexto cosmológico em diálogo com as expressóes artísticas e sensoriais de sociedades indígenas.

O exemplo de Barcelos Neto é elucidativo por estabelecer uma relação simbólica entre a imagem e o pensamento:

A questâo da imagem humana envolve amplos contextos, não se limitando apenas à cura xamânica (...) Parece haver na cultura uma eminente necessidade simbólica de transformar imagens figurativas bi ou tridimensionais em algo vivo ou potencialmente vivo (1999, p.10).

Um importante caminho para os estudos da imagem no âmbito da disciplina antropológica remete às relaçôes que determinados grupos estabelecem com a experiência audiovisual, a partir da delimitação do conceito de visualidade.

As possibilidades de visualização, potencializadas pelos suportes gráficos e audiovisuais, tratam de experiências estéticas da realidade: como reproduções de universos sociocosmológicos (Van Verlthem, 1992), como meios de comunicação com o mundo sobrenatural (Gallois, 1992), como uma advertência constante da impregnação da vida humana pelo mundo espiritual (Langdon, 1992), ou como uma possibilidade de encenação de uma transposição temporal.

A inclusão do suporte audiovisual na antropologia, abordado como fonte de visualidade, expressa significados culturais que incluem, em suas diversas possibilidades, expressóes de realidades diversas. $\mathrm{O}$ estudo sobre a construção dessas diferentes visualidades representa vias de acesso à compreensão de sociedades indígenas em suas múltiplas manifestaçóes: construção de identidades, processos de revisão de autoimagens, categorias de alteridade, noçôes de temporalidade e humanidade. Esses processos permitem que o conjunto de manifestaçóes do pensamento indígena possa ser acessado pelos estudos antropológicos no âmbito das experiências de comunicação audiovisual.

Nesse sentido, as imagens podem desempenhar um papel importante no âmbito da disciplina e no contexto de comunicação intercultural: ora como um privilegiado instrumento de $\mathrm{Co}-$ municação entre grupos indígenas, ora como uma via de acesso às concepçóes e categorias nativas investigadas pela pesquisa etnológica.

\section{Anthropology and visuality in the indige- nous context}

abstract The elaboration and presentation of sounds and images is approached here as part of a constantly reflexive movement, which goes beyond the products of film production to reveal a polyphonic process of the construction of images and autoimages. In this analysis, emphasis has been given to forms of representation in ethnographic film and video, a genre that develops in parallel to the documentary movement, in which the central elements are realism and the analysis of difference. In the development of this article, the analysis of forms of representation reveals a complex process of communication, which articulates different concepts of the visual. The emergence of a reflexive audio-visual practice among indigenous societies not only bears influence on the terms of inter-ethnic dialogue and dialogue with the dominant culture but is also relevant in the development of new approaches to the role of the image in the field of anthropological investigation, which in turn go beyond forms of representation to inscribe themselves on conceptions of the visual.

Keywords Audio-visual. Partnership. Realism. Conceptions of the visual. Difference. 


\section{Referências bibliográficas}

ALBERT, Bruce. O ouro canibal e a queda do céu: uma crítica xamânica à economia política da natureza. In: ALBERT, Bruce; RAMOS, Alcida Rita (Org.) Pacifcando o branco. São Paulo: Editora da Unesp, 2002, p. 239-274.

APPADURAI, Arjun. Here and now. In: Modernity at large: cultural dimensions of globalization. Mineapolis: University of Minnesota Press, 1996, p. 1-11.

AUGÉ, Marc. A guerra dos sonhos. São Paulo: Papirus, $1997.128 \mathrm{p}$.

AUMONT, Jacques et al. A estética do filme. Campinas: Papirus, $1995.310 \mathrm{p}$.

BANKS, Marcus. Which films are the etnographic films? In: CRAWFORD, Peter Ian; TURTON, David. Film as ethnography. Manchester: Manchester University Press, 1992. p. 116-129.

BARCELOS NETO, Aristóteles. Do sonho à figuração, visão e poder entre os xamâs Waurá: elementos para uma estética xinguana. São Paulo, 1999. Paper - Faculdade de Filosofia, Letras e Ciências Humanas, Universidade de São Paulo.

BHABHA, Homi. O local da cultura. Belo Horizonte: Editora da UFMG, 1998. 395 p.

CAIUBY NOVAES, Sylvia. Quando os cineastas são índios. Disponível em: <http://www.mnemocine. com.br/osbrasisindigenas/caiuby.htm>. Acesso em: 31/03/2000.

CARNEIRO DA CUNHA, Manuela. Etnicidade: da cultura residual mas irredutível. In: Antropologia do Brasil. São Paulo: Editora Brasiliense, 1986a, p. 97-108.

Parecer sobre os critérios de identidade étnica. In: Antropologia do Brasil. São Paulo: Editora Brasiliense, 1986b, p. 113-119.

Negros, estrangeiros: os escravos libertos e sua volta à África. São Paulo: Editora Brasiliense, 1995. 231 p.

CARROLL, Noël. Nonfiction film and postmodernist skepticism. In: BORDWELL, David; CARROLL, Noël (Ed.). Post-theory: reconstructing film studies. Madison: The University of Wisconsin Press, 1996, p. 283-306.

CHALFEN, Richard. Picturing culture through indigenous imagery: a telling history. In: CRAWFORD, Peter Ian; TURTON, David. Film as ethnography. Manchester: Manchester University Press, 1992, p. 222-241.

DE BRIGARD, Emile. The history of ethnographic film. In: HOCKINGS, Paul (Org.). Principles of visual anthropology. The Hauge: Mounton, 1975. p.13-43.
FELDMAN BIANCO, Bela; MOREIRA LEITE, Mirian. Desafios da imagem: fotografia, iconografia e vídeo nas ciências sociais. Campinas: Papirus, 1998. 319 p.

FRANCE, Claudine. Cinema e antropologia. Campinas: Editora da Unicamp, 1998. $435 \mathrm{p}$.

FREIRE, Marcius. Por Tarzan ou por Nanook: o filme antropológico a procura de seu punctum. In: BOAVENTURA, Ilka. (Org.). Ética e Estética na Antropologia. Florianópolis: PPGAS/UFSC, 1998. p. 129-132.

FROTA, Mônica. Taking aim e a aldeia global: a apropriação cultural e política da tecnologia de vídeo pelos índios kayapós. Disponível em: <http://www.mnemocine.com.br/osbrasisindigenas/frota.htm $>$. Acesso em: $31 / 03 / 2000$.

GALLOIS, Dominique T. Arte iconográfica Waiāpi”. In: VIDAL, Lux (Org.). Grafismo Indigena: estudos de antropologia estética. São Paulo: Studio Nobel, 2002, p. 209-230.

Desafios e traduções da diferença cultural. Comunicação. IX Congresso de Antropologia: Barcelona, IX congrès d'Antropologia FAAEE. Cultura y politica, 2002.

GALLOIS, Dominique T.; CARELLI, Vincent. Vídeo nas Aldeias: a experiência Waiāpi. Cadernos de Campo, Sáo Paulo: PPGAS/USP, v. 2, p. 25-36, 1993.

Diálogo entre Povos Indígenas: A experiência de dois encontros mediados pelo vídeo. Revista de Antropologia, São Paulo, v. 38, n. 1, p. 205-238. 1995

. Índios eletrônicos: a rede indígena de comunicação. Sexta Feira. São Paulo, v. 2, p. 26-31, 1998.

GINBURG, Faye. Videoparentesco: um ensaio sobre A Arca dos Zo'é e Eu Já Fui Seu Irmão. Cadernos de Antropologia e Imagem, Rio de Janeiro, v. 6, p. 171-181, 1995

GOW, Peter. Cinema da floresta: filme, alucinação e sonho na Amazônia peruana. Revista de Antropologia, v. 38, n. 2, p. 37-54, 1995.

A geometria do corpo. In: NOVAES, Adauto (Org.). A outra margem do Ocidente. São Paulo: Companhia das Letras, 1999, p. 299-315.

HANNERZ, Ulf. Fluxos, fronteiras e híbridos: palavraschave para uma antropologia transnacional. Mana, Rio de Janeiro, v. 3, n. 1, p. 7-39, 1997.

HENLEY, Paul. Cinematografia e pesquisa etnográfica. Cadernos de Antropologia e Imagem, Rio de Janeiro, v. 9, p. 29-49, 1999.

HYMES, Dell. A Antropologia da comunicação. In: DANCE, Frank E. X. (Org.). Teoria da comunicação humana. São Paulo: Cultrix, 1967, p. 9-56. 
Antropologia e Visualidade no Contexto Indígena | I 5 I

INGOLD, Tim. Key debates in anthropology. London and New York: Routledge, 1998. 302 p.

LANGDON, Jean. A cultura Siona e a experiência alucinógena. In: VIDAL, Lux (Org.). Grafismo indigena:estudos de antropologia estética. São Paulo: Studio Nobel, 1992, p.67-87.

LEACH, Edmund. Cultura e comunicação. Zahar Editores: Rio de Janeiro, 1978. $111 \mathrm{p}$.

LOIZOS, Peter. Admissible Evidence? Film in Anthropology. In: CRAWFORD, Peter Ian; TURTON, David. Film as Ethnography. Manchester: Manchester University Press, 1992, p. 50-65.

MACDOUGALL, David. Transcultural Cinema. Princeton: Princeton University Press, 1998. 318 p.

MARCUS, George; FISCHER, Michael J. Anthropology as cultural critique: an experimental moment in the human sciences. Chicago: University Chicago Press, 1986. $194 \mathrm{p}$.

MEAD, Margaret. Visual anthropology in a discipline of words”. In: HOCKINGS, P. (Org.). Principles of visual anthropology. Mounton Publishers: Chicago, 1985, p. 3-10.

MÜLLER, Regina Pólo. Tayngava: a noção de representação na arte gráfica assurini do Xingu". In: VIDAL, Lux (Org.). Grafismo indigena: estudos de antropologia estética. São Paulo: Studio Nobel, 1992, p. 231-248.

NICHOLS, Bill. Ideology and the image: social representation in the cinema and other media. Bloomington: Indiana University Press, 1981. 334 p.

The etnographer's tale. In: TAYLOR, Lucien

(Org.). Visualizing teory: selected Essays from V.A.R. 1900-1994. New York and London: Routledge, 1994, p. 60-83.

PRICE, Sally. Arte primitiva em centros civilizados. Rio de Janeiro: Editora da UFRJ, 2000. 199 p.

RENOV, Michael. Re-thinking documentary. Wide Angle, v. 8, n. 3-4, p. 71-77, 1986.

Toward a poetics of documentary. In: Michael Renov (Org.) Theorizing documentary. New York: Routledge, 1993, p. 12-36.

ROUCH, Jean. Entrevista concedida a Jean-Paul Colleyn. Cadernos de Antropologia e Imagem, Rio de Janeiro, v. 1 , p. $65-88,1995$.

SINGER, André. Anthropology in broadcasting. In: CRAWFORD, Peter Ian; TURTON, David. Film as Ethnography. Manchester: Manchester University Press, 1992, p. 264-273.

TURNER, Terence. Imagens desafiantes: a apropriação Kaiapó do vídeo. Revista de Antropologia. São Paulo, v. 36, p .81-121, 1993.
VIDAL, Lux (Org.). Grafismo indigena: estudos de antropologia estética. São Paulo: Studio Nobel, 1992. 296 p.

VAN VELTHEM, Lúcia Hussak. Das cobras e lagartas: a iconografia Wayana. In: VIDAL, Lux (Org.). Grafismo indígena: estudos de antropologia estética. São Paulo: Studio Nobel, 1992, p. 53-65.

O belo é a fera: a estética da produção e da predação entre os Wayana. 1995. $338 \mathrm{f}$. Tese (Doutorado em Antropologia) - Faculdade de Filosofia, Letras e Ciências Humanas, Universidade de São Paulo, São Paulo.

VERNET, Marc. Cinema e Narração. In: AUMONT, Jacques et alli. A estética do filme. Campinas: Papirus, 1995, p. 89-156.

WEINBERGER, Eliot. The camera people. In: TAYLOR, Lucien (Ed.) Visualizing theory: selected essays from V.A.R. 1900-1994. New York: Routledge, 1994, p. 3-26.

WORTH, Sol; ADAIR, John. Navajo Filmakers. American Anthropologist, v. 72, p. 9-37, 1979.

\section{Filmografia citada}

A Arca dos Zo'é. Direção: Vincent Carelli e Dominique Gallois. Produção: Centro de Trabalhos Indigenistas. São Paulo: CTI, 1993. 1 videocassete (22 min.), VHS, son, color.

Arrivée d'un train en gare à la Ciotat. Direção: Louis Lumière. Paris, 1895. (50 min.). $35 \mathrm{~mm}$.

L'arroseur arrosé. Direção: Louis Lumière. Paris, 1895. (40 min.). $35 \mathrm{~mm}$.

The cook in trouble. Direção: Georges Méliès. Paris, 1904. (3 min.). $35 \mathrm{~mm}$.

Disappearing vorld (série). Granada Television, Great Britain, 1970. 50 filmes de aproximadamente $52 \mathrm{~min}$. $35 \mathrm{~mm}$.

Hepari Idubrada, obrigado irmão. Realização e imagens: Divino Tserewahú. Produção: Centro de Trabalhos Indigenistas. São Paulo: CTI, 1998. 1 videocassete (17 min.), VHS, son, color.

Jaguar. Direção: Jean Rouch. Produção: Les Films de la Pléïade Paris, 1967. (93 min.) $35 \mathrm{~mm}$.

Jane Moraita : nossas festas. Direção: Kasiripinã Waiãpi. Produção: Centro de Trabalhos Indigenistas. São Paulo: CTI, 1995. 1 videocassete (32 min.), VHS, son, color.

The magic lantern. Direção: Georges Méliès. Paris, 1903. $35 \mathrm{~mm}$. Silent, black and white 


\section{52 Sílvia Pizzolante Pellegrino}

Le maitres fous. Direção: Jean Rouch. Produção: Les Films de la Plêiade, Paris, 1955. (36 min.). $35 \mathrm{~mm}$. color

The man with the movie camera. Direção: Dziga Vertov. Produção: Ukrainian film studio VUFKU URSS, 1928. (68 min.) $35 \mathrm{~mm}$. son, black and white

Nanook of the North. Direção: Robert Flaherty. USA, France, 1922. (79 min.) $35 \mathrm{~mm}$. silent, black and white.

The Navajo film themselves. Direção: Sol Worth and John Adair. 1972. 16 mm, silent, black and white.

Netsilik Eskimos (série). Asen Balikci e Guy Mary Produced under grants from the National Science Foundation and the Ford Foundation (U.S.) and by Education Development Center, Inc. of Newton, MA, in association with the National Film Board of Canada;. EUA/Canadá, 1963-68. 21 half-hour parts, $35 \mathrm{~mm}$. son, black and white.

Petit à petit. Direção: Jean Rouch. Produção: Les Films de la Plêiade, Paris, 1954. (80 min.). $35 \mathrm{~mm}$. son, color.

Rituais e festas bororo. Direção: major Luiz Thomas Reis. Produção: Conselho Nacional de Proteção aos Índios, Brasil, 1917. (20 min.).16 mm, silent, black and white.

Sortie d'usine. Direção: Louis Lumière. Paris, 1895. Silent, black and white.
Taking aim: aldeia global. Direção: Mônica Frota. 1993. (41 min,). Hi-8/NTSC, son, color.

Tem que ser curioso. Direção: Caimi Waiassé. Produção: Centro de Trabalhos Indigenistas. São Paulo: CTI, 1996. (16 min,). VHS, son, color.

Voyage à travers l'impossible. Direção: Georges Méliès. Paris, 1904. (24 min.). $35 \mathrm{~mm}$, silent, black and white.

Wapté Mnhônô: iniciação do jovem Xavante. Realização e Fotografia: Bartolomeu Patira, Caimi Waiassé, Divino Tserewahú, Jorge Protodi, Winti Suyá. Produção: Centro de Trabalhos Indigenistas CTI. São Paulo, 1999, Vídeo (75 min.), VHS, Cor.

\section{Notas}

O presente texto é um resumo da dissertação de Mestrado, de mesmo título, apresentada ao Programa de Pós-Graduação em Multimeios da Universidade Estadual de Campinas/UNICAMP em fevereiro de 2003. Para uma leitura mais completa do tema proposto, inclusive das entrevistas realizadas, consultar o texto integral da dissertação.

autor Sílvia Pizzolante Pellegrino

Doutoranda em Ciência Social (Antropologia Social)/USP

Recebido em 13/02/2006

Aceito para publicação em 17/10/2007 